\title{
Mini-Abstract:
}

Utilizing a standardized dataset based on 27 univocally defined complications, we analyzed clinical, oncological, surgical, and outcome data obtained from European referral centers for gastric cancer belonging to the Gastrectomy Complications Consensus Group in order to provide a benchmark for complications and outcomes associated with gastrectomy for cancer. 


\begin{abstract}
Objective: Utilizing a standardized dataset based on a newly developed list of 27 complications, this study analyzed data to provide a western benchmark for evaluating complications and outcomes associated with gastrectomy for cancer.
\end{abstract}

Summary Background Data: The absence of a standardized system for recording gastrectomyassociated complications makes it difficult to compare results from different hospitals and countries.

Methods: Using a secure online platform (www.gastrodata.org), referral centers for gastric cancer in 11 European countries belonging to the Gastrectomy Complications Consensus Group recorded clinical, oncological, and surgical data, and outcome measures at hospital discharge and at 30 and 90 days postoperatively. This retrospective observational study included all resections over a 2-year period.

Results: A total of 1349 gastrectomies performed between January 2017 and December 2018 were entered into the database. Neoadjuvant chemotherapy was administered to 577 patients $(42.8 \%)$. Total $(46.1 \%)$ and subtotal (46.4\%) gastrectomy were the predominant resections. D2 or D2+ lymphadenectomy was performed in almost $80 \%$ of operations. The overall complications incidence was 29.8\%; 402 patients developed 625 complications, with the most frequent being non-surgical infections (23\%), anastomotic leak $(9.8 \%)$, other postoperative abnormal fluid from drainage and/or abdominal collections $(9.3 \%)$, pleural effusion (8.3\%), postoperative bleeding (5.6\%), and other major complications requiring invasive treatment (5.6\%). The median Clavien-Dindo score and Comprehensive Complications Index were IIIa and 26.2, respectively. In-hospital, 30-day, and 90-day mortality were $3.2 \%, 3.6 \%$, and $4.5 \%$, respectively.

Conclusions: The use of a standardized platform to collect international data on perioperative complications allows for meaningful comparisons across institutions and countries. 


\section{Incidence and Grading of Complications after Gastrectomy for Cancer Using the GASTRODATA}

\section{Benchmark: A European Retrospective Observational Study}

Gian Luca Baiocchi, MD¹, Simone Giacopuzzi, $\mathrm{MD}^{2}$, Daniel Reim, $\mathrm{MD}^{3}$, Guillaume Piessen, $\mathrm{PhD}^{4}$, Paulo Matos da Costa, $\mathrm{PhD}^{5}$, John V. Reynolds, MCh, FRCSI ${ }^{6}$, Hans-Joachim Meyer, $\mathrm{PhD}^{7}$, Paolo Morgagni, $\mathrm{PhD}^{8}$, Ines Gockel, $\mathrm{MBA}^{9}$, Lucio Lara Santos, $\mathrm{PhD}^{10}$, Lone Susanne Jensen, $\mathrm{PhD}^{11}$, Thomas Murphy, MD, FRCSI ${ }^{12}$, Domenico D’Ugo, $\mathrm{MD}^{13}$ Riccardo Rosati, $\mathrm{MD}^{14}$ Uberto Fumagalli Romario, $\mathrm{MD}^{15}$, Maurizio Degiuli, $\mathrm{PhD}^{16}$, Wojciech Kielan, $\mathrm{MD}^{17}$, Stefan Mönig, $\mathrm{MD}^{18}$, Piotr Kołodziejczyk, $\mathrm{PhD}^{19}$, Wojciech Polkowski, $\mathrm{PhD}^{20}$, Manuel Pera, $\mathrm{PhD}^{21}$, Paul M. Schneider, MD ${ }^{22}$, Bas Wijnhoven, $\mathrm{PhD}^{23}$, Wobbe O de Steur, $\mathrm{MD}^{24}$, Suzanne S. Gisbertz, $\mathrm{PhD}^{25}$, Henk Hartgrink, PhD ${ }^{25}$, Johanna W. van Sandick, $\mathrm{PhD}^{26}$, Maristella Botticini, $\mathrm{PhD}^{28}$, Arnulf H. Hölscher, MD, FRCS ${ }^{27}$, William Allum, MD, $\mathrm{FRCS}^{29}$ and Giovanni De Manzoni, $\mathrm{MD}^{2}$

${ }^{1}$ Department of Clinical and Experimental Sciences, Surgical Clinic, University of Brescia, and 3rd Division of General Surgery, Spedali Civili di Brescia, Brescia, Italy

${ }^{2}$ Department of Surgery, General and Upper G.I. Surgery Division, University of Verona, Verona, Italy

${ }^{3}$ Surgical Department, Klinikum Rechts der Isar, Technical University Munich, Munich, Germany

${ }^{4}$ Department of Digestive and Oncological Surgery, Univ. Lille, and Claude Huriez University Hospital,

Lille, France

${ }^{5}$ Faculdade Medicina, Universidade Lisboa, and General Surgery Department, Hospital Garcia de Orta,

Lisbon, Portugal

${ }^{6}$ Department of Surgery, St. James's Hospital and Trinity College Dublin, Ireland

${ }^{7}$ Generalsekretär, Deutsche Gesellschaft für Chirurgie, Berlin, Germany

${ }^{8}$ GB Morgagni-L Pierantoni Surgical Department, Forlì, Italy

${ }^{9}$ Department of Visceral, Transplant, Thoracic and Vascular Surgery, University Hospital of Leipzig, Leipzig, Germany

${ }^{10}$ Experimental Pathology and Therapeutics Group and Surgical Oncology Department, Portuguese Institute of Oncology, Porto, Portugal

${ }^{11}$ Department of Surgery, Aarhus University Hospital, Aarhus C, Denmark

${ }^{12}$ Department of Surgery, Mercy University Hospital, Cork City, Republic of Ireland

${ }^{13}$ Department of General Surgery, Fondazione Policlinico Gemelli, Rome, Italy

${ }^{14}$ Department of Gastrointestinal Surgery, San Raffaele Hospital, Milan, Italy

${ }^{15}$ Department of Digestive Tract Surgery, IEO, Milan, Italy

${ }^{16}$ Department of Oncology, Head, Digestive and Surgical Oncology, University of Torino, and San Luigi University Hospital, Orbassano, Italy

${ }^{17}$ 2nd Department of General and Oncological Surgery, Wroclaw Medical University, Wroclaw, Poland

${ }^{18}$ Division of Abdominal Surgery, University Hospital of Geneva, Geneva, Switzerland

${ }^{19}$ Department of Surgery I, Jagiellonian University, Krakow, Poland

${ }^{20}$ Department of Surgical Oncology, Medical University of Lublin, Lublin, Poland

${ }^{21}$ Department of Surgery, Section of Gastrointestinal Surgery, Hospital Universitario del Mar, Universitat Autònoma de Barcelona, and Hospital Universitario del Mar Medical Research Institute (IMIM), Barcelona, Spain

${ }^{22}$ Center for Visceral, Thoracic and Specialized Tumor Surgery, Hirslanden Medical Center, Zurich, Switzerland

${ }^{23}$ Department of Surgery, Erasmus Medical Center, Rotterdam, The Netherlands

${ }^{24}$ Department of Surgery, Leiden University Medical Center, Leiden, The Netherlands

${ }^{25}$ Department of Surgery, Academic Medical Center, Amsterdam, The Netherlands

${ }^{26}$ Department of Surgery, Netherlands Cancer Institute, and Antoni van Leeuwenhoek Hospital, Amsterdam, The Netherlands 
${ }^{27}$ German Center for Esophageal and Gastric Surgery, Agaplesion Markuskrankenhaus, Frankfurt, Germany

${ }^{28}$ IGIER, Università Bocconi, Milan, Italy

${ }^{29}$ Department of Surgery, Royal Marsden NHS Foundation Trust, London, United Kingdom

Correspondence and reprints to: Gian Luca Baiocchi, 3rd Division of General Surgery, Spedali Civili di Brescia, P.le Spedali Civili 1, 20125 Brescia, Italy.

Phone: ++39-030-399-5618

Fax: ++39-030-3996123

E-mail: gianluca.baiocchi@unibs.it

Short running head: Benchmarking Gastrectomy Complications

Conflict-of-Interest Statement: The authors declare no conflict of interest. 


\section{INTRODUCTION}

Gastric cancer is the fifth most frequently diagnosed cancer and the fourth cause of cancer-related death globally. ${ }^{1}$ Limited progress has been made with non-surgical therapies, and surgical resection enhanced by standardized lymphadenectomy is still the gold standard in the therapeutic pathway. ${ }^{2,3,4}$ However, radical gastrectomy with lymphadenectomy is a complex intervention. Many clinical series indicate that postoperative courses differ significantly between eastern and western centers, with 30-day mortality rates being around $1 \%{ }^{5,6}$ and $5 \%$, respectively. ${ }^{7,8}$ The driving factors behind this difference have not been clarified, being possibly due to both patient- and surgeon-related features. ${ }^{9}$ While mortality is easier to quantify, the reporting of morbidity rates has notably suffered from the lack of a standardized system, with morbidity rates ranging from $10 \%$ to $40 \% .{ }^{9,10}$ Clearly, the absence of a standardized system for recording perioperative complications associated with radical gastrectomy generates wide variations in evaluating the impact of complications on outcomes. ${ }^{11,12,13}$

To address this issue, in 2015, the European Chapter of the International Gastric Cancer Association (IGCA) launched the EGCA-1 project entitled: "Complications after gastrectomy for cancer. European perspective". The Gastrectomy Complications Consensus Group (GCCG) was established with an initial group of 34 gastric cancer referral centers in 13 European countries. Centers were invited based on the volume of gastric cancer surgery, the availability of a data collection system, and a proven scientific interest in the field. After two rounds of online Delphi consensus meetings and four main meetings (Verona, Lisbon, Leiden, Forli) of the GCCG in 2017 and 2018, a standardized list comprising 27 perioperative complications associated with gastrectomy for cancer was developed and published. ${ }^{14}$ Next, a secure online platform for entering clinical, oncological, and surgical data, the incidence and relevant features of the complications and clinical outcomes, was set up in 2018 and launched in early 2019.

The EGCA-1 project consists of two main studies - a retrospective study comprising all resections for gastric cancer performed at participating centers in 2017 and 2018, and an observational prospectively collected database that is currently ongoing and will include all gastrectomies performed in 
2019 and 2020. This article presents the main findings from the retrospective study. The final goal is the definition of a western benchmark for complications and outcomes associated with radical gastrectomy for cancer.

\section{METHODS}

\section{Participating Centers}

Table 1 lists the 27 centers in 11 European countries that entered the data using the standardized GastroData platform; these centers belong to the Gastrectomy Complications Consensus Group.

\section{[TABLE 1 HERE]}

\section{Ethics / Study Approval}

The study conforms to the ethical guidelines of the 1975 Declaration of Helsinki ( $6^{\text {th }}$ revision, 2008) as reflected in the IRB approvals that were obtained from the participating centers. The study also meets the guidelines for clinical research required by the institutions with which all the authors are affiliated.

\section{GastroData Online Platform}

A secure web-based platform (www.gastrodata.org) was developed by a specialized software firm (www.Fluxedo.com) to facilitate uniform data collection. The GCCG members provided the critical input for building the platform, which was then tested severally with a few retrospective and prospective cases for each center before its official launch in early 2019. Each study participant was then given personal login credentials to enter data. All data, including center, surgeon and patient data, were strictly anonymous and managed through secure codes. Each center only had access to its patient episodes.

The GastroData online platform consists of six sections reporting the following data:

\section{A. Clinical Data}

Patient demographics, body mass index (BMI), American Society of Anesthesiologists (ASA) score, Charlson Comorbidity Index, Prognostic Nutritional Index, weight loss, pharmacological therapy at admission, previous supramesocolic surgeries, other major surgeries, Karnofsky Performance Score (KPS), and Eastern Cooperative Oncology Group (ECOG) Performance Status. 


\section{B. Oncological and Surgical Data}

Preoperative histology (WHO classification), cTNM, diagnostic methods, neoadjuvant chemotherapy, radiotherapy, and chemoradiotherapy, surgical approach, timing, duration, type of procedure, associated resections, lymphadenectomy, reconstruction, duodenal stump closure, anastomoses, drains, feeding jejunostomy, hyperthermic intraperitoneal chemotherapy, final histology, pTNM or ypTNM, number of harvested and pathological nodes, and Enhanced Recovery After Surgery (ERAS) accomplishment.

\section{Twenty-seven Perioperative Complications}

Detailed clinical (e.g., postoperative day, presentation, transfer to ICU), radiological (e.g., diagnostic tools), and therapeutic (e.g., type of treatment) data on each of the 27 complications previously published by the GCCG, ${ }^{14}$ as well as the complication grading according to the Clavien-Dindo scale. $^{15}$

D. E. F. Outcomes at Discharge and at 30 and 90 days Postoperatively

Comprehensive Complications Index (CCI) ${ }^{16,17}$ adjuvant chemotherapy, radiotherapy, chemoradio therapy, number of hospital readmissions, number and types of re-interventions (gastrectomy-related or not), escalation of level of care, blood products utilization, postoperative hospitalization (days), discharge location, survival, causes of death, KPS, and ECOG Performance Status.

\section{Study Design}

This was a retrospective observational study that included all resections for gastric cancer performed at participating centers in 2017 and 2018. The primary endpoints of this study were as follows: (i) incidence and grading of the 27 perioperative complications; (ii) number and type of re-interventions; (iii) number

of hospital re-admissions; (iv) mortality (total and cause-specific) during hospital stay and at 30 days and 90 days postoperatively; (v) blood product utilization; and (vi) escalation in level of care.

\section{Statistical Analysis}

Data entry was checked at each center to ensure consistency and avoid biases. Missing entries affected mainly the information on pharmacological therapy at admission, KPS, and ECOG Performance Status, 
which were not considered in the statistics. Continuous variables are reported as mean, median, and range. Frequencies and percentages are reported for categorical variables. Statistical analysis was performed using STATA software (version 12, StataCorp LLC, College Station, Texas).

\section{RESULTS}

A total of 1349 patient episodes, referring to all gastric resections for gastric cancer performed in 2017 and 2018 at the 27 participating centers, were entered into the database. The median and mean patient episodes per center were 47 and 52. Detailed clinical, oncological, and surgical data are presented in Table 2 (Table A1 in the Supplemental Digital Content provides similar data by splitting the group into complicated and non-complicated cases).

\section{[TABLE 2 HERE]}

Our findings revealed a male patient predominance $(60.9 \%)$, with almost half of cases $(49.2 \%)$ having BMI $>25 \mathrm{~kg} / \mathrm{m}^{2}, 91.3 \%$ with almost one comorbidity, 1 of 4 patients with a Charlson Comorbidity Index of $\geq 5$, and 1 of $3(36.2 \%)$ patients with an ASA score of $\geq 3$. Weight loss was observed in $40.8 \%$ of cases (in $16.2 \%$ of cases, severe weight loss [ $>10 \%]$ was recorded).

Clinical staging was $\mathrm{T} 1$ in only $8.9 \%$ of cases, whereas advanced gastric cancers were clinically diagnosed in more than $80 \%$ of cases. Preoperative chemotherapy was administered to $42.8 \%$ of patients. Open surgery was performed in $80.2 \%$ of cases, with total and subtotal gastrectomy being almost equally reported $(46.1 \%$ and $46.4 \%)$. D2 or D2+ lymphadenectomy was performed in $79.7 \%$ of patients. Surgical drains were used in $69.3 \%$ of cases, and more than $70 \%$ ERAS items were accomplished in $46.4 \%$ of patients. Final pathological reports showed $\mathrm{pT} \geq 2$ in $74.9 \%$ and $\mathrm{N} \geq 1$ in $55.6 \%$ of cases, whereas $12 \%$ of cases were classified as metastatic. Median and mean harvested nodes were 31.0 and 32.9. R0 resection was performed in $92.1 \%$ of patients.

Table 3 presents the relevant statistics regarding the 27 complications recorded. A total of 402 patients $(29.8 \%)$ developed at least one complication. A total of 625 episodes of complication were reported. A Clavien-Dindo grade of $\geq 3$ was reported in $63.9 \%$ of complicated cases. Surgical re- 
intervention was necessary in 105 cases $(7.8 \%)$ and transfer to ICU in 84 cases $(6.2 \%)$. Mortality rates were $3.2 \%$ during the hospital stay, $3.6 \%$ at 30 days postoperatively, and $4.5 \%$ at 90 days postoperatively.

\section{[TABLE 3 HERE]}

Table 4 shows the incidence and median grading of the 27 complications grouped by three categories: intraoperative, postoperative general, and postoperative surgical.

\section{[TABLE 4 HERE]}

Intraoperative complications were rare (about $2 \%$ of cases). The most frequent complications with an incidence greater than 5\% were non-surgical infections (23\%), anastomotic leak $(9.8 \%)$, other postoperative abnormal fluid from drainage and/or abdominal collections without gastrointestinal leak(s) (9.3\%), pleural effusion requiring drainage $(8.3 \%)$, postoperative bleeding requiring urgent transfusions or invasive treatment (5.6\%), other major complications requiring re-interventions or invasive procedures $(5.6 \%)$, and respiratory failure requiring reintubation $(5.4 \%)$.

The four most frequent surgical complications (anastomotic leak, abdominal collections unrelated to leaks, postoperative bleeding, and other major complications) accounting for $30.3 \%$ of adverse events are analyzed in detail in Table 5.

\section{[TABLE 5 HERE]}

Mortality rates associated with these four most frequent surgical complications were $32.8 \%$, $5.2 \%, 22.8 \%$, and $11.4 \%$, respectively. In $73.6 \%, 67.2 \%, 65.7 \%$, and $71.4 \%$ of anastomotic leak, abdominal collections unrelated to leaks, postoperative bleeding, and other major complications, a total or extended total gastrectomy was performed. An invasive procedure was necessary to treat these four complications in $68.9 \%, 31.9 \%, 100 \%$ and $100 \%$ of cases. A surgical re-intervention was necessary in $42.6 \%, 13.7 \%, 57.1 \%$, and $62.8 \%$ of cases. Finally, the median postoperative hospital stay was $32,20,19$, and 22.5 days, whereas the median CCI was 45.4, 26.2, 42.7, and 39.7, respectively. 


\section{DISCUSSION}

As shown by a few national surveys, radical surgery for gastric cancer is still surprisingly associated with high morbidity and mortality rates $(2 \%$ to $7 \%)$ in western centers. ${ }^{18,19,20}$ These data are significantly different from those reported by eastern centers, where mortality rates are always lower or around $1 \%{ }^{5,6}$ Beyond likely differences in histological features and patient-related risk factors, there may be notable differences pertaining to surgical, and hence, improvable, factors.

Yet, comparing eastern and western results requires foremost a common language. Indeed, whereas mortality rates come from usually undisputable data, morbidity is defined in different ways across centers, countries, studies and in the literature. The universally employed classification system for complications, the Clavien-Dindo score, is particularly useful for assessing the severity grade of a complication based on the therapeutic needs in each adverse event. At the same time, since the score applies to any surgical field, it is not meant to define univocally whether a certain postoperative clinical picture in a specific surgical subfield, such as surgery for gastric cancer, should be considered a complication or not. ${ }^{21}$

Whereas there is a standardized taxonomy to record and study complications associated with esophagectomy based on the works of Low et al, ${ }^{22,23}$ to date, there is no comparable uniform taxonomy to record and analyze complications associated with gastrectomy. This study is the first study that uses a newly developed and standardized list of 27 gastrectomy-associated complications and the online GastroData platform to record data in a uniform way. ${ }^{14}$ The retrospective phase of the study involved 27 gastric cancer referral centers in 11 European countries (Table 1). The centers entered data on all 1349 gastric resections for gastric cancer performed in 2017 and 2018.

Three main findings emerge. First, the postoperative morbidity rate was $29.8 \%$, with $62.9 \%$ of the 625 complications having a Clavien-Dindo grade III or higher (Table 3). Second, the participating centers had lower in-hospital (3.2\%), 30-day (3.6\%), and 90-day (4.5\%) postoperative mortality rates compared to rates reported in European national surveys. These rates can help to establish a reliable benchmark in 
the West for gastrectomy-associated mortality. Third, the gap between mortality and morbidity rates in eastern and western centers remains evident.

The patient group analyzed in this study is a typical western population, in which 70-year-old, stout patients, with various comorbidities were predominant. Young patients with BMI $<20 \mathrm{~kg} / \mathrm{m}^{2}$, an ASA score of 1, and a Charlson Comorbidity Index of 0 comprised less than $10 \%$ of the study population, whereas these characteristics are typically present, on average, in $50 \%$ of patients in eastern series. ${ }^{24,25}$ The clinical and oncological features of the 1349 patients analyzed in this study were also typically western; at least half of patients had lost weight, half of them underwent neoadjuvant chemotherapy, $60 \%$ had T3/T4 cancer, while only $20 \%$ of patients had early gastric cancers; corresponding values of these parameters in the eastern series are $20 \%, 20 \%, 30 \%$, and $60 \% .{ }^{25}$ The proximal localization of the tumor or linitis plastica was reported in $60 \%$ of cases, against an average of $30 \%$ in the eastern series. Finally, $80.2 \%$ of patients in this series underwent open surgery, and $79.7 \%$ underwent D2 or D2+ lymphadenectomy, contrasting with the eastern series in which the most frequent intervention was laparoscopic gastrectomy, the percentage of D1 lymphadenectomy was at least $40 \%$, and the percentage of D2+ lymphadenectomy was lower than $5 \% .{ }^{25}$

Understanding the factors associated with these higher mortality and morbidity rates in the West is thus critical. ${ }^{26}$ The list of the most frequent complications presented in this study can help address this issue. As evident from Table 4, general (49.4\%) and surgical (48.5\%) complications equally contributed to morbidity. One out of 5 patients with complications had non-surgical infections (renal/urinary, pulmonary, and gastrointestinal), with symptoms and germ isolation, and 1 patient out of 7 had respiratory complications needing pleural drainage or re-intubation. In contrast, cardiovascular events were surprisingly rare (1.6\% in total). These figures are similar to those recently reported by Gertsen et al. from the DUCA registry. ${ }^{7}$ There is no obvious line of action regarding some of the most frequent postoperative general complications, such as infections and major respiratory problems. One suggestion would be to collect preoperative swabs from the cutis, mouth, stool, and urine from pre-hospitalized patients undergoing surgery as a way to reduce postoperative infections. The frequency of respiratory 
complications may be lowered by boosting the minimally invasive approach, imposing abstinence of smoking before surgery, providing adequate pain management and ERAS programs, and planning respiratory pre-habilitation for all patients undergoing gastric resection. ${ }^{27}$

In contrast, the most frequent surgical complications were anastomotic leaks, abdominal collections unrelated to anastomotic leaks, postoperative bleeding, and other complications such as evisceration, diaphragmatic hernia, and feeding jejunostomy-related complications. One out of 3 patients with complications had one of these conditions, which were associated with 35 of the 43 in-hospital deaths $(81.4 \%)$.

Anastomotic leaks was the most frequent surgical complication (reaching $13.3 \%$ of the adverse events if duodenal stump leak is taken into account). Mortality associated with leaks is notably high $(32.8 \%)$. About $90 \%$ of anastomotic leaks were at the esophagojejunal anastomosis, and $83.6 \%$ occurred after total or extended total gastrectomy. Many patients with anastomotic leak (68.9\%) required reintervention, and outcomes for these patients measured with different indicators were notably poor (Table 5). The data from this multicenter western series suggest the need for a deeper reflection on anastomotic techniques. ${ }^{28}$ A portion of leaks may be due to patient-related factors that cannot be easily modified (e.g., comorbidities) or are only partially modifiable (nutritional status). However, a significant portion of leaks was evidently linked to the employed surgical technique, calling for action regarding the improvement in the learning of surgical techniques. ${ }^{29,30,31}$ The remaining three most frequent surgical complications were also associated with poor outcome: abdominal drain were removed, on average, at postoperative day 12 , ICU transfer was necessary in $10.3 \%, 31.4 \%, 31.4 \%$ of cases, and hospitalization and CCI were significantly higher than in non-complicated cases.

One recurring risk factor for surgical complication is the total or extended total gastrectomy. ${ }^{32}$ Total or extended total gastrectomy were performed in about $60-70 \%$ of complicated cases in our series. Actions toward quality improvement of the surgical techniques seem mandatory. Prominent international scientific organizations can clearly play a major role on this issue. As shown in Table 3, and previously 
reported, the impact of postoperative surgical complications on a variety of outcomes is notable, even in high-volume centers. $^{33,34,35,36,37}$

The present study does have limitations. Other than requiring participating centers to check data entry accurately, there was no method in place for auditing individual institutional data. In addition, the study was not designed and did not include cancer survival.

During the 12th World Congress of the International Gastric Cancer Association held in Beijing in 2017, the Gastrectomy Complications project received the endorsement of the Executive Committee of the IGCA to disseminate this standardized list of complications worldwide. The ultimate goal of the project is to develop a risk factor model. As shown in Table A1 (Supplemental Digital Contentl) that provides statistics comparing complicated versus non-complicated patients, the richness of the GastroData study can help assess modifiable risk factors and the best treatment options.

\section{ACKNOWLEDGEMENTS}

We are grateful to the data managers and administrative staff at the GCCG centers for their advice and personal contributions to the dataset. Recognition must be given to the non-profit organization RicerChiAmo (www.ricerchiamobrescia.it) for funding the development of the online platform www.GASTRODATA.org Special thanks extended to Andrea Pozzetti and Lorenzo D’Onofrio (www.Fluxedo.com) for developing and technically supporting the online platform during the study. We thank Editage (www.editage.com) for English language editing. 


\section{REFERENCES}

1. Ferlay J, Soerjomataram I, Dikshit R, et al. Cancer incidence and mortality worldwide: sources, methods and major patterns in GLOBOCAN 2012. Int J Cancer 2015; 136:E359-386.

2. De Manzoni G, Marrelli D, Baiocchi GL, et al. The Italian Research Group for Gastric Cancer (GIRCG) guidelines for gastric cancer staging and treatment: 2015. Gastric Cancer 2017; 20:2030.

3. Baiocchi GL, D’Ugo D, Coit D, et al. Follow-up after gastrectomy for cancer. The Charter Scaligero Consensus Conference. Gastric Cancer 2016; 19:15-20.

4. Marrelli D, Polom K, de Manzoni G, et al. Multimodal treatment of gastric cancer in the west: Where are we going? World J Gastroenterol. 2015; 21:7954-69.

5. Sano T, Sasako M, Yamamoto S, et al. Gastric cancer surgery: morbidity and mortality results from a prospective randomized controlled trial comparing D2 and extended para-aortic lymphadenectomy - Japan Clinical Oncology Group study 9501. J Clin Oncol. 2004; 22:27672773.

6. Park JH, Lee HJ, Oh SY, et al. Prediction of postoperative mortality in patients with organ failure after gastric cancer surgery. World J Surg. 2020 Jan 28. doi: 10.1007/s00268-020-05382-9. [Epub ahead of print]

7. Gertsen E, Goense L, Brenkman HJF, et al. on behalf of the Dutch Upper Gastrointestinal Cancer Audit (DUCA) group. Identification of the clinically most relevant postoperative complications after gastrectomy: a population-based cohort study. Gastric Cancer 2020; 23:339-348.

8. Norero E, Vega EA, Diaz C, et al. Improvement in postoperative mortality in elective gastrectomy for gastric cancer: Analysis of predictive factors in 1066 patients from a single centre. Eur J Surg Oncol. 2017; 43:1330-1336. 
9. Strong VE, Song KY, Park CH, et al. Comparison of gastric cancer survival following R0 resection in the United States and Korea using an internationally validated nomogram. Ann Surg. $2010 ; 251: 640-646$.

10. Brenkman HJF, Gisbertz S, Slaman AE, et al. on behalf of the Dutch Upper Gastrointestinal Cancer Audit (DUCA) group. Postoperative outcomes of minimally invasive gastrectomy versus open gastrectomy during the early introduction of minimally invasive gastrectomy in the Netherlands: A population-based cohort study. Ann Surg. 2017; 266:831-838.

11. Papenfuss WA, Kukar M, Oxenberg J, et al. Morbidity and mortality associated with gastrectomy for gastric cancer. Ann Surg Oncol 2014; 21:3008-3014.

12. Bruce J, Russell EM, Mollison J, et al. The measurement and monitoring of surgical adverse events. Health Technol Assess. 2001; 5:1-194.

13. Koch CG, Li L, Hixson E, et al. What are the real rates of postoperative complications: elucidating inconsistencies between administrative and clinical data sources. J Am Coll Surg. $2012 ; 214: 798-805$.

14. Baiocchi GL, Giacopuzzi S, Marrelli D, et al. International consensus on a complications list after gastrectomy for cancer. Gastric Cancer 2019; 22:172-189.

15. Dindo D, Demartines N, Clavien PA. Classification of surgical complications: a new proposal with evaluation in a cohort of 6336 patients and results of a survey. Ann Surg. 2004; 240:205213.

16. Slankamenac K, Graf R, Barkun J, et al. The comprehensive complication index: a novel continuous scale to measure surgical morbidity. Ann Surg. 2013; 258:1-7.

17. Clavien PA, Vetter D, Staiger R, et al. The comprehensive complication index (CCI $($ ): Added value and clinical perspectives 3 years down the line. Ann Surg. 2017; 265:1045-1050.

18. Baiocchi GL, Giacopuzzi S, Marrelli D. Cutoff values of major surgical complications rates after gastrectomy. Updates Surg. 2018; 70:251-255. 
19. Baiocchi GL, Giacopuzzi S, Marrelli D, et al. Complications after gastrectomy for cancer: Italian perspective. Updates in Surgery 2017; 69:285-288.

20. Messager M, de Steur WO, van Sandick JW, et al. Variations among 5 European countries for curative treatment of resectable oesophageal and gastric cancer: A survey from the EURECCA Upper GI Group (EUropean REgistration of Cancer CAre). Eur J Surg Oncol. 2016; 42:116-122.

21. Zhou J, Yu P, Shi Y, et al. Evaluation of Clavien-Dindo classification in patients undergoing total gastrectomy for gastric cancer. Med Oncol. 2015; 32:120.

22. Low DE, Kuppusamy MK, Alderson D, et al. Benchmarking complications associated with esophagectomy. Ann Surg. 2019; 269:291-298.

23. Low DE, Alderson D, Cecconello I, et al. International consensus on standardization of data collection for complications associated with esophagectomy: Esophagectomy Complications Consensus Group (ECCG). Ann Surg. 2015; 262:286-294.

24. Suda K, Kitagawa Y. How do we bridge the West and the East in the treatment for gastric cancer? Ann Surg Oncol. 2017; 24:864-865.

25. Bickenbach K, Strong V. Comparisons of gastric cancer treatments: East vs West. J Gastric Cancer 2012; 12:55-62.

26. Suh YS, Yang HK. Screening and early detection of gastric cancer. East versus West. Surg Clin North Am 2015; 15:1053-1065.

27. Mortensen K, Nilsson M, Slim K, et al. Consensus guidelines for enhanced recovery after gastrectomy: Enhanced recovery after surgery (ERAS) society recommendations. Br J Surg. 2014; 101:1209-1229.

28. Fumagalli U, Baiocchi GL, Celotti A, et al. Incidence and treatment of mediastinal leakage after esophagectomy: Insights from the multicenter study on mediastinal leaks. World J Gastroenterol. $2019 ; 25: 356-366$. 
29. Park JH, Jeong SH, Lee YJ, et al. Safety and efficacy of post-anastomotic intraoperative endoscopy to avoid early anastomotic complications during gastrectomy for gastric cancer. Surg Endosc. 2019 Dec 13. doi: 10.1007/s00464-019-07319-3. [Epub ahead of print]

30. Syn NL, Wee I, Shabbir A, et al. Pouch versus no pouch following total gastrectomy: metaanalysis of randomized and non-randomized studies. Ann Surg. 2019; 269:1041-1053.

31. Palmer P, Egger M, Philips P, et al. Predictive preoperative and intraoperative factors of anastomotic leak in gastrectomy patients. Am J Surg. 2019 Dec 31. doi:10.1016/j.amjsurg.2019.12.030. [Epub ahead of print]

32. Li SS, Costantino CL, Mullen JT. Morbidity and mortality of total gastrectomy: A comprehensive analysis of 90-Day outcomes. J Gastrointest Surg. 2019; 23:1340-1348.

33. Short MN, Aloia TA, Ho V. The influence of complications on the costs of complex cancer surgery. Cancer. 2014; 120:1035-1041.

34. Jensen LS, Nielsen H, Mortensen PB, et al. Enforcing centralization for gastric cancer in Denmark. Eur J Surg Oncol. 2010; 36:S50-S5454.

35. Nelen SD, Heuthorst L, Verhoeven RHA, et al. Impact of centralizing gastric cancer surgery on treatment, morbidity, and mortality. J Gastrointest Surg. 2017; 21:2000-2008.

36. Pasquer A, Renaud F, Hec F, et al. Is centralization needed for esophageal and gastric cancer patients with low operative risk? A nationwide study. Ann Surg. 2016; 264:823-830.

37. Li SS, Udelsman BV, Parikh A, et al. Impact of postoperative complication and completion of multimodality therapy on survival in patients undergoing gastrectomy for advanced gastric cancer. J Am Coll Surg. 2020 Feb 6. doi: 10.1016/j.jamcollsurg.2019.12.038. [Epub ahead of print]. 
TABLE 1: Gastrectomy Complications Consensus Group (GCCG): Data Contributing Centers

\begin{tabular}{|c|c|c|c|}
\hline Denmark & Aarhus & Aarhus University Hospital & Lone Susanne Jensen \\
\hline \multirow[t]{2}{*}{ France } & Lille & Centre Hospitalier Régional & Christophe Mariette \\
\hline & & Universitaire & Guillaume Piessen \\
\hline \multirow[t]{3}{*}{ Germany } & Frankfurt & Agaplesion Markus Hospital & Arnulf H. Hölscher \\
\hline & Leipzig & University Hospital of Leipzig & Ines Gockel \\
\hline & Munich & Technical University of Munich & Daniel Reim \\
\hline \multirow[t]{2}{*}{ Ireland } & Cork City & Mercy University Hospital & Thomas Murphy \\
\hline & Dublin & Trinity College Dublin & John V. Reynolds \\
\hline \multirow[t]{8}{*}{ Italy } & Brescia & Spedali Civili Hospital & Gian Luca Baiocchi \\
\hline & Forlì & Morgagni Pierantoni Hospital & Paolo Morgagni \\
\hline & Milano & IEO & Uberto Fumagalli \\
\hline & & San Raffaele Hospital & Riccardo Rosati \\
\hline & Torino & University of Torino & Maurizio Degiuli \\
\hline & Roma & Policlinico Gemelli & Domenico D’Ugo \\
\hline & Verona & University of Verona & Giovanni De Manzoni \\
\hline & & & Simone Giacopuzzi \\
\hline \multirow[t]{5}{*}{ The Netherlands } & Amsterdam & Academic Medical Center & Suzanne S. Gisberz \\
\hline & & Netherlands Cancer Institute & Johanna W. van Sandick \\
\hline & Leiden & Leiden Univers. Medical Center & Wobbe O de Steur \\
\hline & & & Henk Hartgrink \\
\hline & Rotterdam & Erasmus Medical Center & Bas Wijnhoven \\
\hline \multirow[t]{3}{*}{ Poland } & Krakow & Jagiellonian University & Piotr Kołodziejczyk \\
\hline & Lublin & Medical University of Lublin & Wojciech Polkowski \\
\hline & Wroclaw & Wroclaw Medical University & Wojciech Kielan \\
\hline \multirow[t]{2}{*}{ Portugal } & Lisbon & University of Lisbon & Paulo Matos da Costa \\
\hline & Porto & Portuguese Institute of Oncology & Lucio Lara Santos \\
\hline Spain & Barcelona & Hospital Universitario del Mar & Manuel Pera \\
\hline \multirow[t]{2}{*}{ Switzerland } & Geneva & University Hospital of Geneva & Stefan Mönig \\
\hline & Zurich & Hirslanden Medical Center & Paul M. Schneider \\
\hline United Kingdom & London & Royal Marsden NHS & William Allum \\
\hline
\end{tabular}


TABLE 2: Patient's Clinical, Oncological and Surgical Data $(N=1349)$

\begin{tabular}{|c|c|c|c|c|}
\hline & Number & Percentage & Median & Mean \\
\hline Patients per center & --- & --- & 47.0 & 52.0 \\
\hline Female & 528 & 39.1 & --- & --- \\
\hline Male & 821 & 60.9 & --- & --- \\
\hline Age & --- & --- & 69.0 & 67.3 \\
\hline BMI & --- & --- & 24.9 & 25.4 \\
\hline$<18.5$ & 58 & 4.8 & --- & --- \\
\hline$\geq 18.5,<25$ & 556 & 46.0 & --- & --- \\
\hline$\geq 25,<30$ & 411 & 34.0 & --- & --- \\
\hline$\geq 30,<35$ & 142 & 11.7 & --- & --- \\
\hline$\geq 35,<40$ & 31 & 2.6 & --- & --- \\
\hline$\geq 40$ & 11 & 0.9 & --- & --- \\
\hline ASA & --- & --- & 2.0 & 2.2 \\
\hline I & 190 & 14.8 & --- & --- \\
\hline II & 629 & 49.1 & --- & --- \\
\hline III & 438 & 34.2 & --- & --- \\
\hline IV & 25 & 2.0 & --- & --- \\
\hline Charlson comorbidities index & --- & --- & 3.0 & 3.4 \\
\hline 0 & 118 & 8.7 & --- & --- \\
\hline $1-4$ & 888 & 65.8 & --- & --- \\
\hline $5-8$ & 311 & 23.1 & --- & --- \\
\hline $9-13$ & 32 & 2.4 & --- & --- \\
\hline Prognostic nutritional index & --- & --- & 53.5 & 58.7 \\
\hline$<40$ & 66 & 9.5 & --- & --- \\
\hline$\geq 40,<45$ & 86 & 12.4 & --- & --- \\
\hline$\geq 45,<50$ & 109 & 15.7 & --- & --- \\
\hline$\geq 50$ & 434 & 62.4 & --- & --- \\
\hline Weight loss (Yes) & 551 & 40.8 & --- & --- \\
\hline$\leq 10 \%$ & 332 & 24.6 & --- & --- \\
\hline$>10 \%$ & 219 & 16.2 & --- & --- \\
\hline Previous supramesocolic surgeries & 204 & 15.1 & --- & --- \\
\hline Previous major surgeries & 278 & 20.6 & --- & --- \\
\hline Pre-operative tumor histology known & 1190 & 88.2 & --- & --- \\
\hline \multicolumn{5}{|l|}{ Tumor site (multiple answers allowed) } \\
\hline Upper & 228 & 17.3 & --- & --- \\
\hline Middle & 358 & 27.1 & --- & --- \\
\hline Lower & 638 & 48.3 & --- & --- \\
\hline Cardias Siewert 2 & 72 & 5.5 & --- & --- \\
\hline Cardias Siewert 3 & 97 & 7.3 & --- & --- \\
\hline Linitis Plastica & 42 & 3.2 & --- & --- \\
\hline \multicolumn{5}{|l|}{ Tumor size } \\
\hline$<3 \mathrm{~cm}$ & 493 & 46.6 & --- & --- \\
\hline$[3-6 \mathrm{~cm}]$ & 366 & 34.6 & --- & --- \\
\hline$>6 \mathrm{~cm}$ & 199 & 18.8 & --- & --- \\
\hline \multicolumn{5}{|l|}{$\mathrm{cT}$} \\
\hline Tx & 126 & 9.5 & --- & --- \\
\hline $\mathrm{T} 1$ & 118 & 8.9 & --- & --- \\
\hline $\mathrm{T} 2$ & 268 & 20.2 & --- & --- \\
\hline T3 & 565 & 42.5 & --- & --- \\
\hline
\end{tabular}




\begin{tabular}{|c|c|c|c|c|}
\hline & Number & Percentage & Median & Mean \\
\hline $\mathrm{T} 4$ & 251 & 18.9 & --- & --- \\
\hline \multicolumn{5}{|l|}{$\mathrm{cN}$} \\
\hline $\mathrm{Nx}$ & 190 & 14.5 & --- & --- \\
\hline No & 481 & 36.6 & --- & --- \\
\hline $\mathrm{N}+$ & 643 & 48.9 & --- & --- \\
\hline \multicolumn{5}{|l|}{$\mathrm{cM}$} \\
\hline $\mathrm{Mx}$ & 309 & 23.3 & --- & --- \\
\hline M0 & 906 & 68.4 & --- & --- \\
\hline $\mathrm{M}+$ & 110 & 8.3 & --- & --- \\
\hline Pre-operative chemotherapy (Yes) & 577 & 42.8 & --- & --- \\
\hline Patient completed more than $80 \%$ (Yes) & 529 & 91.7 & --- & --- \\
\hline Pre-operative radiotherapy (yes) & 16 & 1.2 & --- & --- \\
\hline Patient completed more than $80 \%$ (Yes) & 16 & 100.0 & --- & --- \\
\hline Pre-operative chemoradiotherapy (Yes) & 15 & 1.1 & --- & --- \\
\hline Patient completed more than $80 \%$ (Yes) & 15 & 100.0 & --- & --- \\
\hline Timing --- Elective & 1317 & 97.6 & --- & -- \\
\hline \multicolumn{5}{|l|}{ Surgical approach } \\
\hline Open & 1081 & 80.2 & --- & --- \\
\hline Laparoscopy & 245 & 18.2 & --- & --- \\
\hline Conversion to open (Yes) & 26 & 10.8 & --- & --- \\
\hline Robotic & 19 & 1.4 & --- & --- \\
\hline Conversion to open (Yes) & 3 & 15.8 & --- & --- \\
\hline \multicolumn{5}{|l|}{ Surgical procedure type } \\
\hline Extended total gastrectomy & 84 & 6.2 & --- & -- \\
\hline Total gastrectomy & 621 & 46.1 & --- & --- \\
\hline Subtotal gastrectomy & 624 & 46.4 & --- & -- \\
\hline Proximal gastrectomy & 17 & 1.3 & --- & --- \\
\hline Surgical procedure duration & --- & --- & 244.5 & 261.2 \\
\hline \multicolumn{5}{|l|}{ Lymphadenectomy } \\
\hline D0 & 46 & 3.5 & --- & --- \\
\hline D1 & 82 & 6.2 & --- & --- \\
\hline D1+ & 140 & 10.6 & --- & --- \\
\hline $\mathrm{D} 2$ & 889 & 67.1 & --- & --- \\
\hline $\mathrm{D} 2+$ & 167 & 12.6 & --- & -- \\
\hline HIPEC (Yes) & 60 & 4.5 & --- & --- \\
\hline \multicolumn{5}{|l|}{ Type of reconstruction } \\
\hline Roux-ex-Y & 1263 & 90.3 & --- & --- \\
\hline Billroth I & 22 & 1.6 & --- & --- \\
\hline Billroth II & 86 & 6.4 & --- & --- \\
\hline Other & 23 & 1.7 & --- & --- \\
\hline \multicolumn{5}{|l|}{ Duodenal stump suture } \\
\hline Manual & 52 & 4.0 & --- & -- \\
\hline Mechanical & 1263 & 96.0 & --- & --- \\
\hline Manual reinforcement (Yes) & 457 & 36.2 & --- & --- \\
\hline Surgical drains (Yes) & 934 & 69.3 & --- & --- \\
\hline Number of surgical drains & --- & --- & 1.0 & 1.7 \\
\hline Feeding jejunostomy (Yes) & 206 & 15.3 & -- & --- \\
\hline ERAS (more than $70 \%$ items completed) & 625 & 46.4 & --- & --- \\
\hline \multicolumn{5}{|l|}{ Postoperative tumor histology (WHO class.) } \\
\hline Adenocarcinoma & 1205 & 90.9 & --- & --- \\
\hline
\end{tabular}




\begin{tabular}{lcccc}
\hline & Number & Percentage & Median & Mean \\
\hline Adenosquamous & 16 & 1.2 & --- & --- \\
Carcinoma with lymphoid stroma & 9 & 0.7 & --- & --- \\
Hepatoid carcinoma & 0 & 0.0 & --- & --- \\
Squamous cells carcinoma & 2 & 0.2 & --- & --- \\
Undifferentiated & 34 & 2.6 & --- & --- \\
Other $^{1}$ & 59 & 4.5 & --- & --- \\
Resection margin & & & & \\
R0 & 1242 & 92.1 & --- & --- \\
R1 & 91 & 6.7 & --- & --- \\
R2 & 16 & 1.2 & --- & --- \\
Number of resected lymph nodes & --- & --- & 31.0 & 32.8 \\
Number of positive lymph nodes & --- & --- & 1.0 & 4.9 \\
Patients without positive lymph nodes & 598 & 44.3 & --- & --- \\
Patients with positive lymph nodes & 751 & 55.7 & --- & --- \\
Pathological staging & & & & \\
Tis & 42 & 3.1 & --- & --- \\
T0 & 49 & 3.7 & --- & --- \\
T1a & 103 & 7.7 & --- & --- \\
T1b & 142 & 10.6 & --- & --- \\
T2 & 166 & 12.4 & --- & --- \\
T3 & 419 & 31.3 & --- & --- \\
T4a & 354 & 26.4 & --- & --- \\
T4b & 64 & 4.8 & --- & --- \\
N0 & 598 & 44.3 & --- & --- \\
N1 & 220 & 16.3 & --- & --- \\
N2 & 212 & 15.7 & --- & --- \\
N3 & 319 & 23.6 & --- & --- \\
M0 & 1178 & 88.0 & --- & --- \\
M1 & 161 & 12.0 & --- & --- \\
\hline
\end{tabular}

${ }^{1}$ In the postoperative tumor histology, "Other" includes benign diseases (8), complete response to neoadjuvant chemo, radio, or chemoradiotherapy (13), neuroendocrine tumors (12), GIST (9), no tumors found on the surgical specimen (7), lymphoma (5), gastric metastases from tumors in other organs (3), small cells tumors (1), and collision tumors (1). 
TABLE 3: Gastrectomy Complications and Outcomes at Discharge, 30-days and 90-days Postoperatively

\begin{tabular}{|c|c|c|c|c|}
\hline Total patient episodes $=1349$ & Number & Percentage & & \\
\hline Patients with no complications & 947 & 70.2 & & \\
\hline Patients developing at least one complication & 402 & 29.8 & & \\
\hline \multicolumn{5}{|l|}{ Clavien-Dindo grading of individual complications ${ }^{1}$} \\
\hline Grade I & 40 & 6.4 & & \\
\hline Grade II & 192 & 30.7 & & \\
\hline Grade IIIa & 135 & 21.6 & & \\
\hline Grade IIIb & 119 & 19.0 & & \\
\hline Grade Iva & 53 & 8.5 & & \\
\hline Grade IVb & 23 & 3.7 & & \\
\hline Grade V & 63 & 10.1 & & \\
\hline All & 625 & --- & & \\
\hline Complications per patient & 1.5 & --- & & \\
\hline Patients requiring blood products & 216 & 16.0 & & \\
\hline Patients requiring surgical re-interventions & 105 & 7.8 & & \\
\hline $\begin{array}{l}\text { Patients requiring endoscopic and/or radiological } \\
\text { Interventions }\end{array}$ & 40 & 2.9 & & \\
\hline Escalation in level of care (mostly to ICU) & 84 & 6.2 & & \\
\hline In-hospital mortality & 43 & 3.2 & & \\
\hline \multicolumn{5}{|l|}{ Discharge location } \\
\hline Home & 1240 & 91.9 & & \\
\hline Secondary medical facility / Rehab & 66 & 4.9 & & \\
\hline \multicolumn{5}{|l|}{ Patients with adverse events during $30-\mathrm{d}$ postop } \\
\hline Re-admissions related to gastrectomy & 93 & 7.1 & & \\
\hline Re-admissions unrelated to gastrectomy & 47 & 3.6 & & \\
\hline Re-interventions & 46 & 3.5 & & \\
\hline Escalation in level of care & 9 & 0.7 & & \\
\hline \multicolumn{5}{|l|}{ Patients alive at $30-\mathrm{d}$ postoperatively } \\
\hline No & 48 & 3.6 & & \\
\hline Yes & 1301 & 96.4 & & \\
\hline \multicolumn{5}{|l|}{ Patients with adverse events during $90-\mathrm{d}$ postop } \\
\hline Re-admissions related to gastrectomy & 40 & 3.1 & & \\
\hline Re-admissions unrelated to gastrectomy & 39 & 3.0 & & \\
\hline Re-interventions & 31 & 2.4 & & \\
\hline Escalation in level of care & 11 & 0.8 & & \\
\hline \multicolumn{5}{|l|}{ Patients alive at 90 -d postoperatively } \\
\hline No & 61 & 4.5 & & \\
\hline \multirow[t]{2}{*}{ Yes } & 1288 & 95.5 & & \\
\hline & Mean & Median & Min & Max \\
\hline Comprehensive Complications Index $(\mathrm{CCI})^{2}$ & 37.3 & 26.2 & 8.7 & 100 \\
\hline Blood products utilization ${ }^{3}$ & 4.2 & 2.0 & 0 & 65 \\
\hline Postoperative hospitalization (days) & 13.5 & 9.0 & 1 & 142 \\
\hline
\end{tabular}

${ }^{1}$ Median Clavien-Dindo score $=$ IIIa.

${ }^{2}$ Values are calculated over the 402 patients who had one or more complications.

${ }^{3}$ Values are calculated over the 216 patients who needed blood products. 
TABLE 4: Incidence of Complications by Category with Grading

\begin{tabular}{|c|c|c|c|c|}
\hline & & $\begin{array}{c}\text { Number } \\
\text { of adverse } \\
\text { events }\end{array}$ & $\begin{array}{c}\% \text { of } \\
\text { adverse } \\
\text { events }\end{array}$ & $\begin{array}{l}\text { Clavien- } \\
\text { Dindo score } \\
\text { (median) }\end{array}$ \\
\hline \multicolumn{5}{|c|}{ Intraoperative } \\
\hline 18. & $\begin{array}{l}\text { Unintended intraoperative damage to major vessels } \\
\text { and/or organs requiring reconstruction or resection }\end{array}$ & 7 & 1.1 & --- \\
\hline 19. & Intraoperative bleeding requiring urgent transfusion & 6 & 0.9 & --- \\
\hline 24. & $\begin{array}{l}\text { Unexpected medical conditions interrupting or changing } \\
\text { the planned procedure }\end{array}$ & 0 & 0 & --- \\
\hline \multicolumn{5}{|c|}{ Postoperative General } \\
\hline 1. & Non-surgical infections ${ }^{1}$ & 144 & 23.0 & II \\
\hline 4. & Pleural effusion requiring drainage & 52 & 8.3 & IIIa \\
\hline 6. & Respiratory failure requiring reintubation & 34 & 5.4 & IVa \\
\hline 10. & $\begin{array}{l}\text { Acute renal insufficiency/renal failure requiring CVVH } \\
\text { / dialysis }\end{array}$ & 18 & 2.9 & IIIa \\
\hline 11. & Need for prolonged intubation ( $>24$ hours after surgery) & 16 & 2.6 & II \\
\hline 15. & Need for tracheostomy & 9 & 1.4 & IVa \\
\hline 16. & Need for CPR & 9 & 1.4 & $\mathrm{~V}$ \\
\hline 17. & Pulmonary embolism & 8 & 1.3 & II \\
\hline 18. & Pneumothorax requiring treatment & 7 & 1.1 & IIIa \\
\hline 20. & Myocardial infarction & 5 & 0.8 & IIIa \\
\hline 21. & Acute myocardial failure with acute pulmonary edema & 3 & 0.5 & II \\
\hline 22. & Cardiac dysrhythmia requiring invasive treatment & 2 & 0.3 & IIIb \\
\hline 23. & Stroke causing patient's permanent deficit & 1 & 0.2 & $\mathrm{~V}$ \\
\hline 23. & Acute liver dysfunction (Child-Pugh $>8$ for $48+$ hours) & 1 & 0.2 & $\mathrm{I}$ \\
\hline \multicolumn{5}{|c|}{ Postoperative Surgical } \\
\hline & Anastomotic leak & 61 & 9.8 & IIIb \\
\hline 3. & $\begin{array}{l}\text { Other postoperative abnormal fluid from drainage, } \\
\text { abdominal collections without gastrointestinal leak(s) } \\
\text { preventing drainage removal and/or requiring treatment }\end{array}$ & 58 & 9.3 & IIIa \\
\hline 5. & Postoperative bleeding requiring invasive treatment & 35 & 5.6 & $\mathrm{IIIb}$ \\
\hline 5. & $\begin{array}{l}\text { Other major complications requiring re-intervention or } \\
\text { other invasive procedures }{ }^{2}\end{array}$ & 35 & 5.6 & IIIb \\
\hline 7. & Postoperative bowel obstruction & 30 & 4.8 & II \\
\hline 8. & Postoperative pancreatic fistula & 25 & 4.0 & II \\
\hline 9. & Duodenal leak & 22 & 3.5 & $\mathrm{IIIb}$ \\
\hline 12. & Delayed gastric emptying (by 10th postoperative day) & 14 & 2.2 & IIIa \\
\hline 13. & Postoperative pancreatitis & 12 & 1.9 & II \\
\hline 14. & Postoperative bowel perforation or necrosis & 11 & 1.8 & IVa \\
\hline \multicolumn{2}{|r|}{ Total } & 625 & & \\
\hline \multicolumn{5}{|c|}{ Precise complication definitions according to the taxonomy agreed upon by the GCCG. ${ }^{14}$} \\
\hline \multicolumn{5}{|c|}{$\begin{array}{l}\text { The number next to each complication indicates the rank of the } 27 \text { major complications according to their } \\
\text { incidence (e.g., "non surgical infections" is the top major complication with } 23 \% \text { of all recorded adverse } \\
\text { events being due to a non-surgical infection). } \\
{ }^{1} \text { They include gastrointestinal, respiratory, renal / urinary and other infections. } \\
{ }^{2} \text { They include evisceration, diaphragmatic hernia, feeding jejunostomy-related complications, and other } \\
\text { major complications requiring re-interventions and/or other invasive procedures. }\end{array}$} \\
\hline
\end{tabular}


TABLE 5: Features of Four Most Frequent Surgical Complications

\begin{tabular}{|c|c|c|c|c|c|}
\hline \multicolumn{6}{|c|}{ Anastomotic Leak } \\
\hline & Number & Percentage & Median & Mean & Range \\
\hline Patients with anastomotic leak & 61 & 9.8 & --- & --- & --- \\
\hline Grade I-II & 10 & 16.4 & --- & --- & --- \\
\hline Grade IIIa-IVb & 41 & 67.2 & --- & --- & --- \\
\hline Grade V & 10 & 16.4 & --- & --- & --- \\
\hline Pod & --- & --- & 6 & 7.6 & {$[1,24]$} \\
\hline \multicolumn{6}{|l|}{ Anastomosis } \\
\hline Esophago-jejuno & 50 & 89.3 & --- & --- & --- \\
\hline Gastro-jejuno & 5 & 8.9 & --- & --- & --- \\
\hline Jejuno-jejuno & 1 & 1.8 & --- & --- & --- \\
\hline \multicolumn{6}{|l|}{ Surgical procedure } \\
\hline Extended total gastrectomy & 11 & 18.0 & --- & --- & --- \\
\hline Total gastrectomy & 40 & 65.6 & --- & --- & --- \\
\hline Subtotal gastrectomy & 8 & 13.1 & --- & --- & --- \\
\hline Proximal & 2 & 3.3 & --- & --- & --- \\
\hline Patients requiring re-interventions & 42 & 68.9 & --- & --- & --- \\
\hline \multicolumn{6}{|l|}{ Treatment (multiple options allowed) } \\
\hline Surgical & 26 & 42.6 & --- & --- & --- \\
\hline Endoscopic & 17 & 27.9 & --- & --- & --- \\
\hline Percutaneous drainage & 10 & 16.4 & --- & --- & --- \\
\hline Nasogastric tube & 12 & 19.7 & --- & --- & --- \\
\hline Feeding jejunostomy & 8 & 13.1 & --- & --- & --- \\
\hline Fasting \& parenteral nutrition & 14 & 23.0 & --- & --- & --- \\
\hline No treatment & 9 & 14.8 & --- & --- & --- \\
\hline \multicolumn{6}{|l|}{ Outcome } \\
\hline Complete leak closure & 38 & 62.3 & --- & --- & --- \\
\hline No leak closure & 12 & 19.7 & --- & --- & --- \\
\hline Unknown & 11 & 18.0 & --- & --- & --- \\
\hline Leak duration (days) & --- & --- & 17.0 & 23.8 & {$[1,100]$} \\
\hline Postoperative hospitalization (days) & --- & --- & 32.0 & 40.5 & {$[1,142]$} \\
\hline CCI & --- & --- & 45.4 & 57.9 & {$[20.9,100]$} \\
\hline Dead patients having this complication & 20 & 32.8 & --- & --- & --- \\
\hline \multicolumn{6}{|c|}{$\begin{array}{c}\text { Other postoperative abnormal fluid from drainage, abdominal collections without gastrointestinal leak(s) } \\
\text { preventing drainage removal and/or requiring treatment }\end{array}$} \\
\hline & Number & Percentage & Median & Mean & Range \\
\hline Patients with this complication & 58 & 9.3 & --- & --- & --- \\
\hline Chylous ascites at pod & 14 & --- & 4.5 & 4.6 & {$[0,15]$} \\
\hline Other abnormal fluid at pod & 34 & --- & 9.0 & 10.3 & {$[0,52]$} \\
\hline Biliary drain at pod & 6 & --- & 1.0 & 2.0 & {$[0,7]$} \\
\hline \multicolumn{6}{|l|}{ Severity score } \\
\hline Grade I-II & 28 & 48.3 & --- & --- & --- \\
\hline Grade IIIa-IVb & 29 & 50.0 & --- & --- & --- \\
\hline Grade V & 1 & 1.7 & --- & --- & --- \\
\hline Drainage removed at center's protocol & 15 & 25.9 & --- & --- & --- \\
\hline Drainage removed at pod & --- & --- & 11.0 & 12.7 & {$[7,23]$} \\
\hline \multicolumn{6}{|l|}{ Surgical procedure } \\
\hline Extended total gastrectomy & 5 & 8.6 & --- & --- & --- \\
\hline
\end{tabular}




\begin{tabular}{|c|c|c|c|c|c|}
\hline Total gastrectomy & 34 & 58.6 & --- & --- & --- \\
\hline Subtotal gastrectomy & 19 & 32.7 & --- & --- & --- \\
\hline Proximal & 0 & 0.0 & --- & --- & --- \\
\hline Patients requiring re-interventions & 18 & 31.0 & --- & --- & --- \\
\hline \multicolumn{6}{|l|}{ Treatment (multiple options allowed) } \\
\hline Surgical & 8 & 13.7 & --- & --- & --- \\
\hline Endoscopic & 2 & 3.4 & --- & --- & --- \\
\hline Percutaneous drainage & 23 & 39.6 & --- & --- & --- \\
\hline Postoperative hospitalization (days) & --- & --- & 20.0 & 24.5 & {$[7,120]$} \\
\hline Escalation in level of care (ICU) & 6 & 10.3 & --- & --- & --- \\
\hline $\mathrm{CCI}$ & --- & --- & 26.2 & 30.7 & {$[8.7,100]$} \\
\hline Dead patients with this complication & 3 & 5.2 & --- & --- & --- \\
\hline \multicolumn{6}{|c|}{ Postoperative bleeding requiring both urgent transfusions and invasive treatment } \\
\hline & Number & Percentage & Median & Mean & Range \\
\hline Patients with postoperative bleeding & 35 & 5.6 & --- & --- & --- \\
\hline Grade I-II & 0 & 0.0 & --- & --- & --- \\
\hline Grade IIIa-IVb & 32 & 91.4 & --- & --- & --- \\
\hline Grade V & 3 & 8.6 & --- & --- & --- \\
\hline Pod & --- & --- & 7.0 & 8.4 & {$[0,70]$} \\
\hline \multicolumn{6}{|l|}{ Surgical procedure } \\
\hline Extended total gastrectomy & 7 & 20.0 & --- & --- & --- \\
\hline Total gastrectomy & 16 & 45.7 & --- & --- & --- \\
\hline Subtotal gastrectomy & 12 & 34.3 & --- & --- & --- \\
\hline Proximal & 0 & 0.0 & --- & --- & --- \\
\hline Hemorrhagic shock & 13 & 37.1 & --- & --- & --- \\
\hline \multicolumn{6}{|l|}{ Source of bleeding } \\
\hline Abdominal wall & 4 & 11.4 & --- & --- & --- \\
\hline Intraluminal & 11 & 31.4 & --- & --- & --- \\
\hline Peritoneal & 19 & 54.3 & --- & --- & --- \\
\hline Unknown & 1 & 2.8 & --- & --- & --- \\
\hline Patients requiring re-interventions & 35 & 100 & --- & --- & --- \\
\hline \multicolumn{6}{|l|}{ Treatment } \\
\hline Surgical & 20 & 57.1 & --- & --- & --- \\
\hline Endoscopic & 9 & 25.7 & --- & --- & --- \\
\hline Endovascular & 3 & 8.6 & --- & --- & --- \\
\hline Incomplete information & 3 & 8.6 & --- & --- & --- \\
\hline Escalation in level of care & 11 & 31.4 & --- & --- & --- \\
\hline Postoperative hospitalization (days) & --- & --- & 19.0 & 26.2 & {$[1,95]$} \\
\hline CCI & --- & --- & 42.7 & 57.6 & {$[26.2,100]$} \\
\hline Dead patients with this complication & 8 & 22.8 & --- & --- & --- \\
\hline \multicolumn{6}{|c|}{ Other major complications requiring re-intervention or other invasive procedures } \\
\hline & Number & Percentage & Median & Mean & Range \\
\hline Patients with other major complications & 35 & 5.6 & --- & --- & --- \\
\hline Evisceration at pod & 6 & 17.1 & 7.0 & 6.2 & {$[2,9]$} \\
\hline Diaphragmatic hernia at pod & 1 & 2.8 & 5.0 & 5.0 & --- \\
\hline Feeding jejun. complication at pod & 2 & 5.7 & 9.5 & 9.5 & {$[5,14]$} \\
\hline $\begin{array}{l}\text { Other major complications at pod } \\
\text { Severity score }\end{array}$ & 26 & 74.3 & 7.5 & 13.4 & {$[1,50]$} \\
\hline
\end{tabular}




\begin{tabular}{lrcccc}
\hline Grade I-II & 0 & 0.0 & --- & --- & --- \\
$\quad$ Grade IIIa-IVb & 32 & 91.4 & --- & --- & --- \\
$\quad$ Grade V & 3 & 8.6 & --- & --- & --- \\
Surgical procedure & & & & & \\
$\quad$ Extended total gastrectomy & 7 & 20.0 & --- & --- & --- \\
$\quad$ Total gastrectomy & 18 & 51.4 & --- & --- & --- \\
$\quad$ Subtotal gastrectomy & 10 & 28.6 & --- & --- & --- \\
$\quad$ Proximal & 0 & 0.0 & --- & --- & --- \\
Patients requiring re-interventions & 35 & 100.0 & --- & --- & --- \\
Treatment (multiple options allowed) & & & & & \\
$\quad$ Surgical & 22 & 62.8 & --- & --- & --- \\
$\quad$ Endoscopic & 3 & 8.6 & --- & --- & --- \\
Postoperative hospitalization (days) & --- & --- & 22.5 & 28.8 & {$[4,83]$} \\
Escalation in level of care (ICU) & 11 & 31.4 & --- & --- & --- \\
CCI & --- & --- & 39.7 & 50.6 & {$[26.2,30]$} \\
Dead patients with this complication & 4 & 11.4 & --- & --- & --- \\
\hline Top four major surgical complications & 189 & 30.2 & --- & --- & --- \\
(incidence $>$ 5\%) & & & & & \\
All 27 complication categories & 625 & --- & --- & --- & -- \\
\hline
\end{tabular}


SUPPLEMENTAL DIGITAL CONTENT

TABLE A1: Complicated vs Uncomplicated Patient's Clinical, Oncological and Surgical Data

\begin{tabular}{|c|c|c|c|c|}
\hline & \multicolumn{2}{|c|}{ Percentage } & \multicolumn{2}{|c|}{ Median } \\
\hline & $\mathrm{C}$ & $\mathrm{NC}$ & $\mathrm{C}$ & $\mathrm{NC}$ \\
\hline Female & 32.1 & 42.1 & --- & --- \\
\hline Male & 67.9 & 57.9 & --- & --- \\
\hline Age & --- & --- & 69.0 & 67.3 \\
\hline BMI & --- & --- & 25.0 & 24.8 \\
\hline ASA & --- & --- & 2.0 & 2.0 \\
\hline Charlson comorbidities index & --- & --- & 4.0 & 3.0 \\
\hline Prognostic nutritional index & --- & --- & 50.6 & 56.1 \\
\hline Weight loss (Yes) & 48.8 & 43.2 & --- & --- \\
\hline Previous supramesocolic surgeries & 17.4 & 14.3 & --- & --- \\
\hline Previous major surgeries & 22.2 & 20.1 & --- & --- \\
\hline Pre-operative tumor histology known & 86.6 & 88.9 & --- & --- \\
\hline \multicolumn{5}{|l|}{ Tumor site (multiple answers allowed) } \\
\hline Upper & 18.7 & 14.6 & --- & --- \\
\hline Middle & 23.8 & 25.5 & --- & --- \\
\hline Lower & 36.8 & 48.0 & --- & --- \\
\hline Cardias Siewert 2 & 6.2 & 4.5 & --- & --- \\
\hline Cardias Siewert 3 & 11.0 & 4.8 & --- & --- \\
\hline Linitis Plastica & 3.5 & 2.7 & --- & --- \\
\hline \multicolumn{5}{|l|}{ Tumor size } \\
\hline$<3 \mathrm{~cm}$ & 42.3 & 48.3 & --- & --- \\
\hline$[3-6 \mathrm{~cm}]$ & 34.2 & 34.7 & --- & --- \\
\hline$>6 \mathrm{~cm}$ & 23.5 & 17.0 & --- & --- \\
\hline \multicolumn{5}{|l|}{$\mathrm{cT}$} \\
\hline $\mathrm{Tx}$ & 8.8 & 9.8 & --- & --- \\
\hline $\mathrm{T} 1$ & 6.3 & 10.0 & --- & --- \\
\hline $\mathrm{T} 2$ & 18.3 & 21.0 & --- & --- \\
\hline $\mathrm{T} 3$ & 45.4 & 41.3 & --- & --- \\
\hline $\mathrm{T} 4$ & 21.3 & 17.9 & --- & --- \\
\hline \multicolumn{5}{|l|}{$\mathrm{cN}$} \\
\hline $\mathrm{Nx}$ & 12.8 & 15.1 & --- & --- \\
\hline N0 & 34.7 & 37.4 & --- & --- \\
\hline $\mathrm{N}+$ & 52.6 & 47.5 & --- & --- \\
\hline \multicolumn{5}{|l|}{$\mathrm{cM}$} \\
\hline $\mathrm{Mx}$ & 21.8 & 24.0 & --- & --- \\
\hline M0 & 66.6 & 69.1 & --- & --- \\
\hline $\mathrm{M}+$ & 11.6 & 6.9 & --- & --- \\
\hline Pre-operative chemotherapy (Yes) & 41.5 & 43.6 & --- & --- \\
\hline Patient completed more than $80 \%($ Yes $)$ & 91.1 & 92.8 & --- & --- \\
\hline Timing --- Elective & 96.8 & 98.1 & --- & --- \\
\hline \multicolumn{5}{|l|}{ Surgical approach } \\
\hline Open & 82.5 & 79.5 & --- & --- \\
\hline Laparoscopy & 16.0 & 19.1 & --- & --- \\
\hline Conversion to open (Yes) & 20.0 & 7.7 & --- & --- \\
\hline
\end{tabular}




\begin{tabular}{|c|c|c|c|c|}
\hline & \multicolumn{2}{|c|}{ Percentage } & \multicolumn{2}{|c|}{ Median } \\
\hline & $\mathrm{C}$ & $\mathrm{NC}$ & $\mathrm{C}$ & $\mathrm{NC}$ \\
\hline Robotic & 1.5 & 1.4 & --- & $\begin{array}{l}--- \\
\end{array}$ \\
\hline Conversion to open (Yes) & 16.7 & 15.4 & --- & --- \\
\hline \multicolumn{5}{|l|}{ Surgical procedure type } \\
\hline Extended total gastrectomy & 9.7 & 4.8 & --- & --- \\
\hline Total gastrectomy & 54.4 & 42.6 & --- & --- \\
\hline Subtotal gastrectomy & 35.2 & 51.1 & --- & --- \\
\hline Proximal gastrectomy & 0.7 & 1.5 & --- & --- \\
\hline Surgical procedure duration & --- & --- & 270 & 240 \\
\hline \multicolumn{5}{|l|}{ Lymphadenectomy } \\
\hline D0 & 3.8 & 3.3 & --- & --- \\
\hline D1 & 5.8 & 6.3 & --- & --- \\
\hline $\mathrm{D} 1+$ & 10.7 & 10.5 & --- & --- \\
\hline D2 & 67.8 & 66.9 & --- & --- \\
\hline D2+ & 11.9 & 12.9 & --- & --- \\
\hline HIPEC (Yes) & 9.7 & 2.2 & --- & --- \\
\hline \multicolumn{5}{|l|}{ Type of reconstruction } \\
\hline Roux-ex-Y & 90.0 & 90.7 & --- & --- \\
\hline Billroth I & 0.5 & 2.1 & --- & --- \\
\hline Billroth II & 7.5 & 6.0 & --- & --- \\
\hline Other & 2.0 & 1.2 & --- & --- \\
\hline \multicolumn{5}{|l|}{ Duodenal stump suture } \\
\hline Manual & 4.3 & 3.8 & --- & --- \\
\hline Mechanical & 95.7 & 96.2 & --- & --- \\
\hline Manual reinforcement (Yes) & 41.1 & 34.4 & --- & --- \\
\hline Surgical drains (Yes) & 76.0 & 68.6 & --- & --- \\
\hline Number of surgical drains & --- & --- & 2 & 1 \\
\hline Feeding jejunostomy (Yes) & 24.9 & 11.2 & --- & --- \\
\hline ERAS (more than $70 \%$ items completed) & 31.8 & 52.5 & --- & --- \\
\hline \multicolumn{5}{|l|}{ Resection margin } \\
\hline R0 & 89.1 & 93.3 & --- & --- \\
\hline R1 & 8.7 & 5.9 & --- & --- \\
\hline R2 & 2.2 & 0.7 & --- & --- \\
\hline Number of resected lymph nodes & --- & --- & 30.0 & 31.0 \\
\hline Number of positive lymph nodes & --- & --- & 1.0 & 1.0 \\
\hline Patients without positive lymph nodes & 42.5 & 45.2 & --- & --- \\
\hline Patients with positive lymph nodes & 57.5 & 54.8 & --- & --- \\
\hline \multicolumn{5}{|l|}{ Pathological staging } \\
\hline Tis & 1.5 & 3.8 & --- & --- \\
\hline T0 & 3.0 & 4.0 & --- & --- \\
\hline T1a & 4.5 & 9.0 & --- & --- \\
\hline $\mathrm{T} 1 \mathrm{~b}$ & 9.3 & 11.2 & --- & --- \\
\hline $\mathrm{T} 2$ & 9.5 & 13.6 & --- & --- \\
\hline T3 & 37.3 & 28.7 & --- & --- \\
\hline $\mathrm{T} 4 \mathrm{a}$ & 28.3 & 25.6 & --- & --- \\
\hline $\mathrm{T} 4 \mathrm{~b}$ & 6.8 & 3.9 & --- & --- \\
\hline N0 & 42.5 & 45.2 & --- & --- \\
\hline N1 & 16.7 & 17.4 & --- & --- \\
\hline N2 & 15.4 & 15.7 & --- & --- \\
\hline N3 & 25.4 & 21.6 & --- & --- \\
\hline
\end{tabular}




\begin{tabular}{lccccc}
\hline & \multicolumn{2}{c}{ Percentage } & \multicolumn{2}{c}{ Median } \\
\hline & $\mathrm{C}$ & $\mathrm{NC}$ & $\mathrm{C}$ & $\mathrm{NC}$ \\
\hline M0 & 84.5 & 89.5 & --- & --- \\
M1 & 15.5 & 10.5 & --- & --- \\
\hline
\end{tabular}

$\mathrm{C}=$ Patients with at least one complication; $\mathrm{NC}=$ Patients with no complications.

${ }^{1}$ In the postoperative tumor histology, "Other" includes benign diseases (8), complete response to neoadjuvant chemo, radio, or chemoradiotherapy (13), neuroendocrine tumors (12), GIST (9), no tumors found on the surgical specimen (7), lymphoma (5), gastric metastases from tumors in other organs (3), small cells tumors (1), and collision tumors (1). 